\title{
PERANCANGAN APLIKASI KNOWLEDGE MANAGEMENT DI INSTANSI KEARSIPAN BERBASIS MODEL CHOO-SENSE MAKING
}

\author{
Eko Nur Hermansyah*1, Danny Manongga ${ }^{2}$,Ade Iriani $^{3}$ \\ ${ }^{1,2,3}$ Magister Sistem Informasi, Fakultas Teknologi Informasi, Universitas Kristen Satya Wacana Salatiga \\ Email: ${ }^{1}$ ekonurhermansyah@gmail.com, ${ }^{2}$ dmanongga@gmail.com, ${ }^{3}$ adeiriani@gmail.com \\ *Penulis Korespondensi
}

(Naskah masuk: 04 September 2019, diterima untuk diterbitkan: 01 Februari 2021)

\begin{abstract}
Abstrak
Instansi Kearsipan memiliki berbagai pengetahuan yang digunakan untuk pengelolaan arsip yang dimilikinya, knowledge management digunakan untuk mengumpulkan, mengelola, dan menyebarluaskan pengetahuan yang dimiliki, sehingga pengetahuan yang dimiliki oleh instansi kearsipan dapat digunakan untuk kemajuan instansi dan tidak hilang, pengetahuan yang dimiliki oleh instansi masih disimpan di almari atau komputer masing-masing pegawai. Penelitian ini dilakukan di Dinas Perpustakaan dan Kearsipan Kota Salatiga. Pengumpulan data dilakukan dengan wawancara petugas kearsipan untuk mengumpulkan data tentang pengetahuan yang dimiliki dan cara penyimpanan serta penyebarluasan yang diterapkan di instansi kearsipan. Analisis data dilakukan dengan mengelompokkan pengetahuan yang dimiliki oleh instansi kearsipan sesuai dengan model Choo-Sense Making, untuk kemudian diterapkan di Confluence sesuai dengan hasil dari pengolahan data dengan model Choo-Sense Making. Hasil dari penelitian ini untuk model Choo-Sense Making pengetahuan di instansi kearsipan dibagi atas 3 tahap yaitu Sense Making yang berisi tentang pengetahuan yang berasal dari luar instansi dibuatkan wadah sebagai media diskusi, chatting, Knowledge Creating berisi tentang pengetahuan-pengetahuan yang dimiliki instansi kearsipan yang telah di dokumentasikan diubah dalam betuk softfile kemudian diunggah kedalam space untuk memudahkan penyimpanan serta penyebarluasan pengetahuan yang dimiliki, dan Decision Making yang berisi tentang jadwal-jadwal instansi dan evaluasi yang dilakukan instansi kearsipan. Hasil dari model Choo-Sense Making dimasukan ke Confluence, memperoleh hasil space yang dapat memudahkan menyimpan pengetahuan yang dimiliki berupa file aplikasi, softfile, serta memudahkan dalam pencarian kembali dan penyerluasan pengetahuan yang dimiliki. Penerapan Choo-Sense Making selain untuk mempermudah penyimpanan dan penyerbaluasan serta komunikasi, dapat mengurangi resiko kehilangan pengetahuan yang dimiliki oleh instansi kearsipan.
\end{abstract}

Kata kunci: Knowledge Management, Model Choo-Sense Making, Confluence, Perpustakaan dan Arsip

\section{THE DESIGN OF KNOWLEDGE MANAGEMENT APPLICATION AT THE ARCHIVAL AGENCY BASED ON CHOO-SENSE MAKING MODEL}

\author{
Abstract
}

Archival Agency has several knowledge that are used to manage the owned archive, knowledge management is used to collect, manage and disseminate the owned knowledge so that the knowledge that the archival agency has can be used for the agency progress and it will not missing, knowledge possessed by agencies is still stored in the wardrobe or computer of each employee. The research is conducted in Dinas Perpustakaan dan Kearsipan Kota Salatiga. Data collecting is conducted by interviewing the archival officer to gather data related to its knowledge, the storage system and dissemination applied in this archival agency. Data analysis is conducted by categorizing the agency knowledge according to Choo-Sense Making model and then it is applied in Confluence in accordance with the result of the data analysis from the Choo-Sense Making model. The result of this research, for Choo-Sense Making model, the knowledge in the archival agency is divided into 3 steps; Sense Making, Knowledge Creating and Decision Making. Sense Making contains knowledge coming from the outside of the agency that has forum as discussion media, chatting. Knowledge Creating contains knowledge that owned by the archival agency that has been documented and changed in the form of softfile then uploaded into space to ease the storage and the knowledge dissemination. Decision Making is about agency schedules and evaluation toward the activity in this archival agency. The result of Choo-Sense Making Model is input into Confluence, get space result that ease to save the 
16 Jurnal Teknologi Informasi dan Ilmu Komputer (JTIIK), Vol. 8, No. 1, Februari 2021, hlm. 15-26

knowledge in the form of application file, softile, and ease to search and disseminate the owned knowledge. The application of Choo-Sense Making eases the storage system, dissemination, and communication. It also reduces the risk of losing knowledge owned by the archival agency.

Keywords: Knowledge Management, Model Choo-Sense Making, Confluence, Library and Archive

\section{PENDAHULUAN}

Kearsipan sebagai institusi pengelola informasi merupakan salah satu bidang penerapan teknologi informasi yang berkembang dengan pesat. Perkembangan dari penerapan teknologi informasi bisa kita lihat dari perkembangan jenis perpustakaan dan kearsipan yang selalu berkaitan dengan teknologi informasinya (Saputra, 2012). Penerapan Teknologi Informasi membantu pegawai untuk mengelola perpustaakaan dan arsip agar pelayanan yang diberikan sesuai dengan keinginan dari pengguna.

Satu dasawarsa terakhir pengelolaan pengetahuan menjadi salah satu metode peningkatan produktifitas suatu organisasi, perusahaan atau instansi. Hal ini dapat dimengerti karena kompetisi tidak lagi mengandalkan sumber daya alam, tetapi berpindah kepada pemanfaatan sumber daya manusia secara optimal. Pemanfaatan sumber daya manusia melalui potensi kreativitas dan inovasi, agar dapat meningkatkan produktivitas suatu organisasi (Elviana, 2010). Knowledge Management digunakan oleh Instansi Kearsipan untuk meningkatkan pelayanan yang dimiliki serta untuk menghindari kehilangan pengetahuan yang dimiliki.

Choo-Sense Making merupakan suatu model yang digunakan untuk mengelola pengetahuan berdasarkan unsur-unsur yang dapat digunakan untuk menciptakan suatu hal yang baru dengan keputusan yang optimal. Model Choo-Sense Making dipilih karena model ini dapat mengelola unsur-unsur pengetahuan yang dimiliki oleh instansi kearsipan sehingga dapat menciptakan pengetahuan dalam bentuk yang baru yang dapat digunakan untuk mengelola pengetahuan yang dimiliki oleh instansi kearsipan itu sendiri. Confluence adalah alat yang bagus dan kuat yang dapat menghasilkan hasil yang maksimal darinya, yang di dalamnya terdapat lapisan demi lapis fungsionalitas, yang canggih yang dapat membantu untuk mengelola pengetahuan yang dimiliki (Caldwell, 2015).

Suatu organisasi, mengelola pengetahuan biasanya sudah dilakukan namun jumlahnya mungkin tidak banyak dan hanya sebatas pada standar operasional yang sangat singkat dan tidak memberikan informasi yang cukup detail. Bahkan terkadang sambil lalu saja dikarenakan kesibukan dan ketidakpedulian pihak manajemen tentang ilmu yang dimiliki oleh seorang pegawai non-manajemen.
Pengetahuan tidak harus dimiliki oleh orang-orang yang memiliki jabatan atau otoritas tinggi namun yang pasti, ia memiliki kompetensi dan spesialisasi terhadap ilmunya. Pengetahuan yang dimiliki oleh setiap individu dalam organisasi merupakan salah satu bentuk dari pengetahuan tacit yang masih terdapat dalam benak pemilik pengetahuannya. Pengelolaan pengetahuan adalah kegiatan untuk mengubah pengetahuan tacit menjadi pengetahuan eksplisit sehingga dapat diketahui dan dimanfaatkan oleh orang lain secara luas (Riyadi, 2016).

Keuntungan dengan dimilikinya knowledge managemenet adalah adanya sebuah gambaran konsisten mengenai organisasi, dimana kemampuan mengelola dan mencari informasi dapat diakses secara langsung ke dalam informasi atau sumber daya organisasi, hubungan secara langsung terhadap laporan-laporan, dan pertanyaan-pertanyaan, hubungan langsung terhadap data yang dibutuhkan dan keahlian seseorang, serta identitas individu dan akses ke isi/ subyek (content) yang dapat dipersonalisasi (Perdana, 2019).

Dinas Perpustakaan dan Kearsipan Kota Salatiga belum mempunyai knowledge management yang dapat mengolah pengetahuan yang dimiliki oleh instansinya sehingga masih ada resiko pengetahuan yang dimiliki oleh instansi akan hilang, selain itu pengetahuan yang dimiliki oleh pegawai tentang pengelolaan arsip masih disimpan di almari atau komputer masing-masing pegawai, hal ini membuat pegawai lain yang menemukan masalah dalam pengolaan arsip harus mencari tahu sendiri penyelesaiannya. Berdasarkan uraian yang ada, penulis tertarik untuk melakukan penelitian tentang bagaimana merancang knowledge management di instansi kearsipan sesuai dengan penerapan ChooSense Making kemudian didesain dengan Confluence, penelitian ini diharapkan dapat mendapatkan gambaran tentang knowledge management yang sesuai dengan instansi kearsipan yang dapat digunakan untuk menghindari hilangnya informasi dan pengetahuan yang dimiliki.

Knowledge Management di Instansi Kearsipan dikembangkan untuk membantu pegawai di Instansi Kearsipan dalam mencari informasi dan bertukar serta berbagi informasi tentang pengelolaan arsip yang dimiliki, dengan penerapan Knowledge Kearsipan pegawai dapat saling berbagi serta saling berdikusi sehingga dalam menghadapi permasalahan 
dalam pengelolaan kearsipan dapat terselesaikan dengan cepat dan pegawai dapat bekerja secara optimal.

Knowledge Management adalah kebiasaan, keahlian/kepakaran, keterampilan, pemahaman, atau pengertian yang diperoleh dari pengalaman, latihan atau melalui proses belajar (Kosasih, 2000). Knowledge Management terbentuk dari suatu pengetahuan, dimana pengetahuan terbagi menjadi tiga jenis, pertama Tacit Knowledge merupakan suatu pengetahuan yang tidak mudah digambarkan dan dibagikan, Pengetahuan ini berupa suatu pengalaman dan keahlian yang dimiliki oleh masing - masing individu dimana pengetahuan tersebut belum terdokumentasikan, pengetahuan ini didapatkan atau berkembang melalui interaksi dan komunikasi dengan orang lain. Explicit Knowledge merupakan suatu pengetahuan yang telah berhasil terdokumentasikan, yang memiliki suatu sifat struktural, sistematis dan mudah untuk dikomunikasikan dan dibagikan kepada orang lain. Pengetahuan ini dapat berupa: buku, jurnal, karya ilmiah, referensi atau lainnya. Pengetahuan ini didapatkan dan berkembang dari isi dan informasi yang ada didalamnya. Potential Knowledge merupakan suatu pengetahuan yang digunakan untuk melakukan suatu analisis data dan mengubah data menjadi sebuah pengetahuan. Pengetahuan ini didapatkan dan berkembang dari hasil analisis terhadap data yang ada (Darudianto, 2013).

Langkah Create The Knowledge Management: Tim KM yang diidentifikasi dalam langkah ini, harus membangun cetak biru dengan menyiapkan perencanaan Knowledge Management. Berikut isu-isu penting dalam langkah ini Customisasi secara detil arsitektur KM, memahami dan menentukan komponen yang diperlukan dalam perusahaan: integrative repositories, content centre, knowledge aggregation dan mining tool, platform yang kolaboratif, direktori pengetahuan,antar muka pengguna, mekanisme pengiriman, dan elemen yang integrative, mendesain sistem untuk interoperabilitas tingkat tinggi, memahami dan menjalankan life-cycle management, memahami kondisi user interface, posisi dan ruang lingkup Knowledge Management harus layak dikerjakan dengan tingkat cost dan benefit yang seimbang, membuat aplikasi sendiri atau membeli dari vendor (Mulyanto, 2009).

Fase pertama berisi semua kegiatan yang berkaitan dengan perolehan pengetahuan. Pengetahuan diperoleh baik dengan "Creating New Knowledge" atau dengan mencari pengetahuan yang ada di basis pengetahuan yang tersedia.Ada empat mode transformasi pengetahuan yang akan menghasilkan pengetahuan yang baru, pertama socialization dimana tacit knowledge diubah menjadi new tacit knowledge, kedua externalization dimana tacit knowledge didokumentasikan menjadi explicit knowledge, ketiga combination dimana explicit knowledge diubah menjadi new explicit knowledge, keempat internalization dimana individu mengintegrasikan explicit knowledge ke dalam rutinitasnya, dan mengubahnya menjadi tacit knowledge (Razmerita, 2016).

Arsip adalah pembawa informasi perusahaan, yang merupakan aset dan kekayaan yang berwujud dan tidak berwujud milik perusahaan. Memasuki era informasi, arsip memiliki peran penting untuk operasi perusahaan, peristiwa kelangsungan hidup dan pengembangan, untuk meningkatkan level manajemen perusahaan, maka perusahaan harus mementingkan hal tersebut (Xiaojun, 2014).

Choo-Sense Making merupakan model yang baik untuk mengelola pengetahuan berdasarkan unsur-unsur yang digunakan untuk menciptakan pengetahuan baru, keputusan yang optimal. Inti model Choo-Sense Making tentang elemen informasi, dipilih dan diperkenalkan dalam tindakan dari konsentrasi dan penyerapan informasi yang berasal dari lingkungan eksternal, pada tahap identifikasi akan digunakan penyaringan pada tingkat individu, komunikasi umum akan dibangun dari pertukaran informasi, dikombinasikan dengan pengalaman sebelumnya (Cristea, 2009).

Choo-Sense Making diusulkan pada tahun 1998, berisi tiga dimensi yaitu, Sense Making yang berisi, upaya untuk memahami informasi yang mengalir dari lingkungan eksternal, serta pertukaran dan negosiasi pengetahuan yang ada, Knowledge Creation yang berisi tentang transformasi pengetahuan pribadi antara individu melalui dialog, wacana, dan berdiskusi. Decision Making yang berisi tentang, memaksimalkan kemampuan yang dimiliki serta perilaku-perilakunya, serta pengetahuan yang perlu di optimalkan yang sudah berjalan dengan cukup baik (Alam, 2015).

Choo-Sense Making terdiri dari tiga tahap yaitu, Sense Making pada tahap inisense-making, adalah salah satu upaya untuk memahami informasi yang mengalir dari lingkungan eksternal. Prioritas yang diidentifikasi dan digunakan untuk menyaring informasi.Individu membangun interpretasi umum dari pertukaran dan bernegosiasi dari bagian-bagian informasi yang dikombinasikan dengan pengalaman sebelumnya. Knowledge Creating, Knowledge Creating dapat dilihat sebagai transformasi pengetahuan pribadi antara individu melalui dialog, wacana, berbagi, dan bercerita. Tahap ini diarahkan oleh visi pengetahuan "seperti" (situasi 
saat ini) dan "menjadi" (masa depan, keadaan yang diinginkan). Penciptaan pengetahuan memperluas spektrum pilihan potensial dalam pengambilan keputusan dengan memberikan pengetahuan baru dan kompetensi baru. Hasilnya umpan proses pengambilan keputusan dengan strategi inovatif yang memperluas kemampuan organisasi untuk membuat informasi, keputusan rasional. Decision Making pengambilan keputusan (decision making) terletak di model pengambilan keputusan rasional yang dapat digunakan untuk mengidentifikasi dan mengevaluasi alternatif dengan mengolah informasi dan pengetahuan yang dikumpulkan sampai saat ini (Legiawan, 2015).

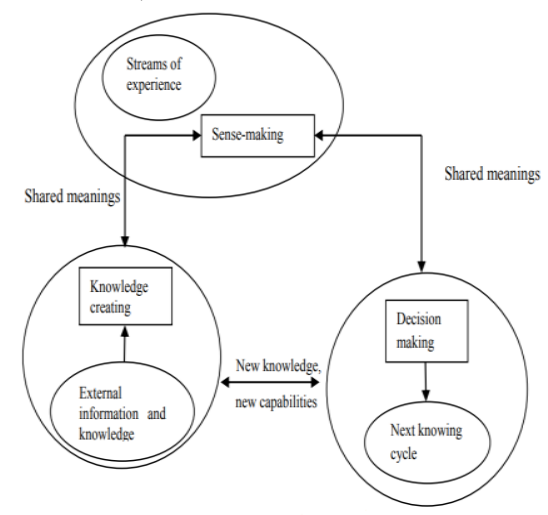

Gambar 1. Choo Sense Making Sumber: Choo (1998) dalam Mohajan

Chun Wei Choo (1998) dalam (Mohajan, 2017) menggambarkan model KM yang menekankan Sense Making, Knowledge Creation And Decision Making. Choo Sense Making berfokus pada bagaimana elemen informasi dipilih dan selanjutnya dimasukkan ke dalam tindakan organisasi. Tindakan organisasi hasil dari konsentrasi dan penyerapan informasi dari lingkungan eksternal. Setiap organisasi mempraktikkan informasi yang masuk ke dalam lingkungannya, untuk membuat pengetahuan baru, dan untuk mengambil keputusan. Ketiganya saling berhubungan memainkan peran strategis untuk membuka pengetahuan organisasi.

Konsep inti dari Confluence, aplikasi online yang dibuat untuk membantu tim, membuat dan mendiskusikan pekerjaannya.Pengetahuanpengetahuan, file diatur dalam space yang merupakan kumpulan halaman terkait.Space terdiri halaman, dokumen di mana tim membuat, mengedit, dan mendiskusikan pekerjaan (Caldwell, 2015).

Penelitian pertama berjudul "Penerapan Model Choo-Sense Making pada Rancangan Knowledge Management System (KMS) untuk Meningkatkan Mutu Kinerja Karyawan di Universitas Suryakancana" memperoleh hasil penerapan Model Choo Sense-Making untuk merancang Knowledge
Management (KM) Tool. Perancangan sistem yang dilakukan yaitu proses penerapan model terhadap rancangan sistem berbasis web dengan menggunakan UML (Unified Modelling Language). Penggunaan dari KM Tool ini melibatkan beberapa pengguna yaitu KM Team, Karyawan, dan Pengambil Keputusan (Decision Maker) sehingga ketika proses penciptaan pengetahuan baru bisa dengan mudah, cepat, dan efisien dengan mereduksi beberapa kegiatan Knowledge Capturing pada saat terjadinya Knowledge Sharing seperti pada saat kegiatan rapat, diskusi, dan seminar (Legiawan, 2015). Kelemahan penelitian pertama belum ada penerapan lebih lanjut sehingga belum ada hasil keberhasilan atau kegagalan dari penerapan Knowledge Managementnya.

Penelitian kedua berjudul Perancangan Knowledge Management System Menggunakan Tools "Book Review": Studi Kasus pada Universitas Bina Nusantara" memperoleh hasil aplikasi Book Review pada KMS Universitas Bina Nusantara dapat mendorong pelaku review buku dan memfasilitasi pelaku review buku dan pembaca review untuk berdiskusi dan berinteraksi lebih optimal (Iskandar, 2014). Kelemahan penelitian kedua hanya menggunakan "Book Review" untuk mendapatkan hasil yang lebih maksimal bisa menggunakan Tools lain.

Penelitian ketiga berjudul " $A$ Road Map for Knowledge Management Systems Design Using Axiomatic Design Approach" memperoleh hasil bahwa enam landasan penting dari manajemen pengetahuan adalah budaya organisasi, struktur organisasi, sumber daya manusia, manajemen dan kepemimpinan, teknologi informasi, dan lingkungan eksternal organisasi (Housmand, 2017). Kelemahan dalam penelitian ini bisa ditambahkan model lain untuk mendapatkan pengetahuan yang baru.

Perbedaan penelitian pertama dengan penelitian penulis adalah penelitian pertama membuat Knowledge management Tools, sedangkan penulis menggunakan Confluence untuk penerapan Knowledge Managementnya. Perbedaan penelitian kedua dengan penelitian penulis adalah penelitian kedua menggunakan tools Book Review sedangkan penulis menggunakan Confluence, selain itu penelitian kedua mengambil data dari Universitas sedangkan penulis dari Instansi Kearsipan. Perbedaan penelitian ketiga dengan penelitian penulis adalah penelitian ketiga menggunakan Axiomatic Design sedangkan penulis menggunakan Choo-Sense Making.

\section{METODE PENELITIAN}

Penelitian menggunakan Model Choo-Sense Making untuk klasifikasi jenis pengetahuan dan 
informasi yang dimiliki oleh Dinas Perpustakaan dan Kearsipan Kota Salatiga yang kemudian detail di kelompokkan sesuai dengan Sense-Making, Knowledge Creating, dan Decision Making. Pengumpulan data dalam penelitian ini dilakukan dengan wawancara, studi literatur, dan observasi. Wawancara dilakukan dengan arsiparis/ petugas yang bekerja di Dinas Perpustakaan dan Kearsipan Kota Salatiga. Observasi dilakukan di perpustakaan untuk memperoleh data yang sesuai. Analisis data dilakukan menggunakan penerapan model Choo-Sense Making dengan mengelompokkan data yang diperoleh selama wawancara dan observasi sesuai dengan SenseMaking, Knowledge Creating, dan Decision Making. Kemudian pengetahuan yang sudah di kelompokkan diterapkan pada Confluence model yang diterapkan untuk Knowledge Management diperoleh dari pengelompokkan pengetahuan sesuai dengan pengelompokkan Choo-Sense Making, kemudian dibuat space yang sesuai dengan kebutuhan instansi untuk menghasilkan space yang dibutukan di instansi kearsipan.

Alur penelitian ini dilakukan dengan :

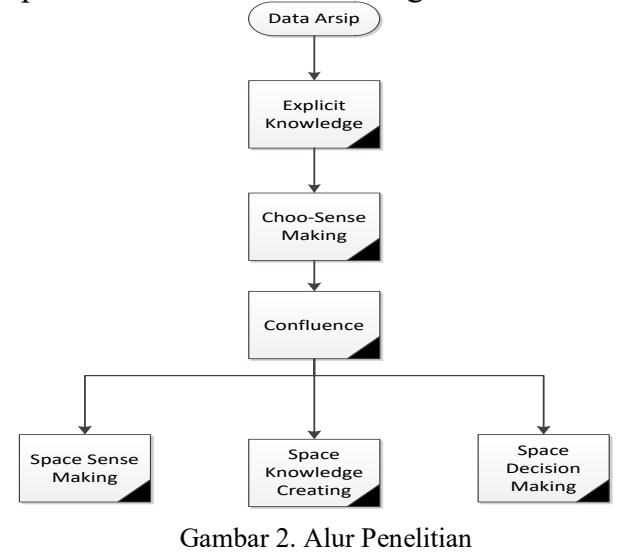

Penelitian dilakukan dengan melakukan wawancara dan observasi di instansi kearsipan untuk memperoleh pengetahuan yang dimiliki, kemudian dikelompokkan sesuai dengan explicit knowledge. Tahap berikutnya adalah penerapan pengetahuan yang telah dikelompokkan secara manual kedalam model Choo-Sense Making untuk memperoleh gambaran knowledge management yang sesuai pada tahap pertama Sense Making pengetahuan dikelompokkan sesuai dengan pengetahuan yang dapat diolah dan memproses pengetahuan eksternal, tahap kedua Knowledge Creating pengelompokkan pengetahuan sesuai dengan pengetahuan yang dapat membangun instansi, mengatur ulang, memilih pengetahuan yang dapat digunakan untuk menyelesaikan masalah di instansi, tahap ketiga adalah Decision Making yang dikelompokkan berisi tentang pengetahuan yang dapat menafsirkan perubahan dan membuat pilihan yang dapat digunakan untuk kepentingan instansi dimasa depan. Tahap selanjutnya adalah penerapan pada Confluence dengan membagi pengetahuan sesuai dengan space.

\section{HASIL DAN PEMBAHASAN}

Pada tahap awal penelitian ini dilakukan dengan cara mengumpulkan studi literatur yang berkaitan dengan Knowledge Management, Arsip dan Kearsipan, Choo-Sense Making, Confluence. Pengumpulan data dilakukan dengan wawancara kepada 3 pegawai instansi kearsipan yang khusus bekerja di instansi kearsipan. Survey dilakukan dengan tahapan merancangan desain dan jenis-jenis pertanyaan, perizinan kepada instansi kearsipan, proses wawancara sebelum perancangan Confluence dan wawancara setelahnya. Pengambilan sampel ini dilakukan dengan purposive sampling dengan kriteria pegawai yang bekerja di instansi kerasipan dan pegawai kearsipan tersebut bekerja pada bidang pengelolaan, pelestarian dan layanan, pengembangan. Hal ini dilakukan untuk memperoleh pengetahuan tentang jenis-jenis arsip dan pengelolaannya, penyebarluasannya, tata cara penyimpanan, jenis kegiatan yang dilakukan instansi kearsipan, cara pegantian/penerimaan pegawai, kerjasama yang dilakukan oleh bidang kearsipan serta bidang-bidang lain yang menyangkut pengelolaan pengetahuan tentang kearsipan dan arsip.

Menghindari hilangnya pengetahuan yang dimiliki oleh bagian kearsipan ketika terjadi mutasi pegawai atau pensiun, pegawai yang diganti instansi kearsipan diperoleh dari ganti internal atau pengajuan pegawai ke badan kepegawaian, untuk menjaga agar pengetahuan yang dimiliki oleh kearsipan tidak hilang maka untuk pegawai-pegawai baru dilakukan pembinaan, pengembangan SDM, pelatihan, sosialisasi, pembinaan bertahap, serta mempelajari dokumen-dokumen tentang pengelolaan arsip dalam bentuk fisik yang disimpan atau softfile yang disimpan di komputer oleh pegawai lain.

Instansi Kearsipan mempunyai kriteria dalam perekrutan pegawai barunya. Pegawai di instansi kearsipan digolongkan dalam tiga jenis yaitu pegawai struktural yang berkedudukan sebagai manajer, pegawai fungsional khusus yang diharuskan mempunyai keahlian dalam bidang kearsipan atau yang mempunyai latar belakang pendidikan kearsipan dan arsiparis, pegawai fungsional umum yang berasal dari latar belakang pendidikan SMA/ ilmu lain yang akan di berikan pelatihan-pelatihan dalam bidang kearsipan. 
Tahapan pertama adalah mengelompokkan pengetahuan yang telah diperoleh dari instansi kearsipan menjadi Explicit Knowledge tahap ini dilakukan untuk memudahkan pengelompokkan data yang sesuai dengan model Choo-Sense Making.

\subsection{Explicit Knowledge}

Pengetahuan yang dimiliki oleh instansi kearsipan Kota Salatiga digunakan oleh pegawai untuk mengelola dokumen-dokumen arsip yang dimiliki oleh instansi kearsipan agar mudah di temukan ketika dibutuhkan, serta disebarluaskan agar dapat digunakan oleh pegawai lain, pengetahuanpengetahuan yang dimiliki oleh instansi kearsipan adalah sebagai berikut, Explicit knowledge dalam instansi kearsipan memperoleh hasil laporan-laporan diklat yang diikuti oleh pegawai, dokumen tentang pengolahan arsip dari Arsip Nasional, Peraturan Gubernur tentang arsip, Peraturan Walikota tentang arsip semua pengetahuan ini sudah didalam bentuk laporan-laporan tertulis. Explicit Knowledge ini nantinya akan di masukkan ke dalam space-space yang ada di dalam Confluence agar dapat digunakan oleh pegawai lainnya.

\subsection{Penerapan model Choo-Sense Making}

Penerapan explicit knowledge ke dalam model Choo-sense Making, yang dapat digunakan untuk memodelkan knowledge management di instansi kearsipan, yang terdiri dari Sense Making, Knowledge Creating dan Decision Making pengelompokkan pengetahuan dilakukan dengan manual sesuai dari arsip pengetahuan yang dimiliki oleh instansi kearsipan dari hasil penelitian di Dinas Perpustakaan dan Kearsipan Kota Salatiga memperoleh hasil sebagai berikut.

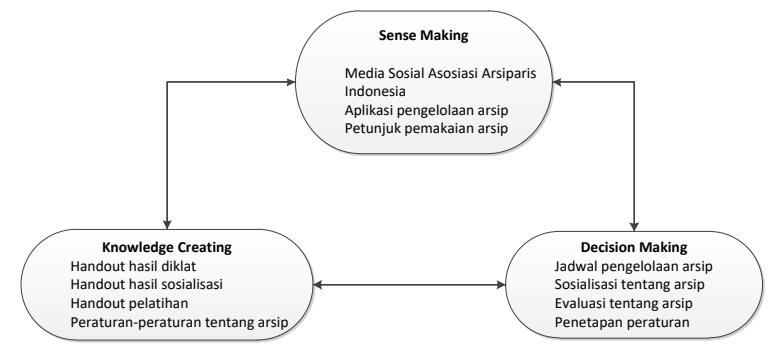

Gambar 3. Penerapan Choo-Sense Making

Gambar 3. menjelaskan hasil dari pengelompokkan pengetahuan berdasarkan ChooSense Making, dengan detail sebagai berikut, tahap pertama adalah pengelompokkan pengetahuan Sense Making pada tahap ini berisi tentang pengetahuan dari lingkungan eksternal yang digunakan sebagai pertukaran dari bagian-bagian informasi, dari hasil penelitian yang termasuk dalam sense making di instansi kearsipan adalah media sosial yang menjadi wadah komunikasi arsiparis yang bernama Asosiasi Arsiparis Indonesia, selain itu juga ada berbagai aplikasi serta petunjuk penggunaannya yang dapat digunakan sebagai pengetahuan untuk pengelolaan arsip. Hasil Sense Making dalam penelitian ini dilakukan dengan pembuatan wadah untuk pegawai bisa chatting dan bertukar pengetahuan serta diskusi, selain itu pembuatan space yang digunakan sebagai penyimpanan aplikasi-aplikasi serta tata cara penggunaannya yang digunakan pegawai untuk mengelola arsip yang dimiliki.

Tahap kedua adalah pengelompokkan pengetahuan Knowledge Creating, pada tahap ini berisi penciptaan pengetahuan yang potensial yang berguna untuk instansi kearsipan, memperoleh hasil instansi kearsipan mempunyai pengetahuan yang sudah terdokumentasikan untuk membantu pengelolaan arsip yang dimilikinya, pengetahuan yang telah terdokumentasikan tersebut berbentuk softfile dan hardcopy yang disimpan oleh arsiparis di almari tersendiri, di komputer, dan dokumen keeper. Pengetahuan tersebut terdiri dari handout hasil diklat, sosialisasi, pelatihan, Peraturan Undang-undang, Peraturan Kepala Arsip, Peraturan Gubernur, Peraturan Walikota. Semua arsip yang digunakan untuk pengelolaan di instansi kearsipan diubah kedalam bentuk softfile kemudian diunggah ke space yang dapat di akses oleh pegawai dan kemudian dapat digunakan untuk menyelesaikan pekerjaan para pegawai dalam pengeloalaan arsip.

Tahap Ketiga adalah pengelompokkan pengetahuan Decision Making, pada tahap ini pengetahuan yang dimiliki diolah dan evaluasi, hasil dari penelitian menemukan pedoman-pedoman jadwal pengelolaan arsip, sosialisasi dari petugas kearsipan kepada keluarahan, kecamatan dan dinasdinas terkait, untuk evaluasi dilakukan untuk koordinasi dengan badan hukum dan pihak-pihak terkait, selain itu juga untuk penyempurnaan peraturan yang sudah ditetapkan, untuk melihat kesesuaian peraturan yang berlaku dengan hasil yang ada dilapangan terkait dengan kearsipan. Pada tahap ini dibuat jadwal-jadwal pada sistem informasi yang dapat dilihat oleh para pegawai tentang jadwal-jadwal kegiatan yang akan dilakukan oleh instansi, didalamnya juga terdapat evaluasi-evaluasi kegiatan yang sudah dilakukan oleh instansi kearsipan. Ketiga tahap tersebut saling berhubungan untuk menciptakan pengetahuan baru dan menyebarluaskannya.

Pengembangan pengetahuan yang dimiliki oleh pegawai kearsipan dilakukan dengan diklat, belajar sendiri dari dokumen yang sudah ada, pengalaman dalam pengelolaan. Penghambat dalam 
penyebarluasan pengetahuan yang dimiliki berasal dari personal pegawai yang tidak mau berbagi pengetahuan yang dimilikinya, pendidikan yang bukan berasal dari bidang kearsipan juga merupakan penghambat.

Pengetahuan yang dimiliki oleh intasi kearsipan masih disimpan di almari tersendiri, serta di komputer masing-masing dari pegawainya sehingga hal itu membuat penyebarluasan pengetahuan yang dimiliki oleh instansi kearsipan menjadi kurang maksimal.

Bentuk Knowledge Management akan yang diterapkan berbentuk space-space yang akan menampung pengetahuan-pengetahuan yang dimiliki oleh instansi kearsipan ataupun pengetahuan yang dimiliki oleh pegawai kearsipan dalam bentuk format digital, selain itu juga terdapat tempat diskusi yang memungkinkan pegawai untuk saling berdiskusi dalam menyelesaikan permasalah dalam bidang kearsipan, di dalamnya terdapat jadwal-jadwal untuk pengeolaan kearsipan dan evaluasi yang berkaitan dengan kegiatan instansi kearsipan itu sendiri.

\subsection{Penerapan Confluence}

Tahapan setelah pembagian pengetahuan sesuai dengan model Choo-Sense Making adalah penerapan di Confluence untuk memperoleh gambaran dari space yang dapat digunakan untuk menyimpan dan menyebarluaskan pengetahuan yang dimiliki oleh instansi sehingga dapat digunakan oleh pegawai lainnya ketika diperlukan. Penerapan dalam Confluence memperoleh hasil sebagai berikut :

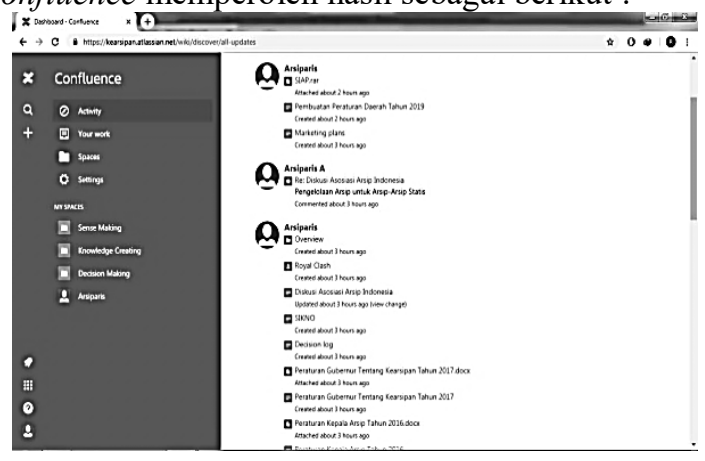

Gambar 4. Tampilan Space

Gambar 4 menampilkan Confluence untuk tampilan space yang berisi aktifitas yang telah di lakukan oleh pengguna akun Arsiparis, Your Work berisi tentang pekerjaan yang dilakukan oleh pengguna berupa unggahan pengetahuan kedalam space-space. Gambar 1 menampilkan Arsiparis mengunggah sebuah file aplikasi berjudul "SIAP" yang digunakan untuk penyimpanan arsip pribadi, serta rencana kegiatan tentang peraturan daerah tahun 2019, Peraturan Gubernur Tentang Kearsipan Tahun
2017, dan Peraturan Kepala Arsip Tahun 2016, didalamnya juga terdapat diskusi antara Arsiparis A dengan Arsiparis.

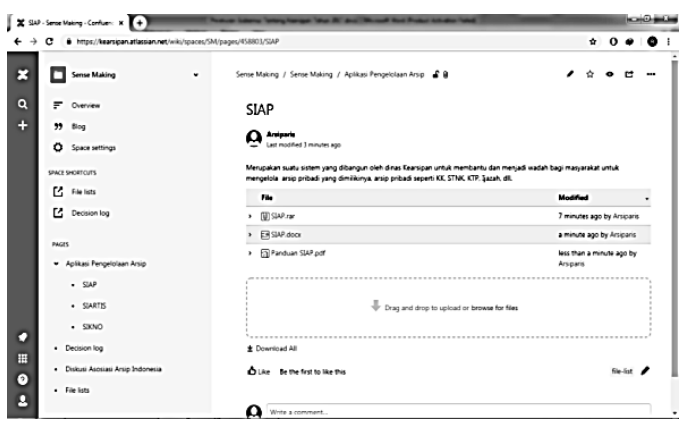

Gambar 5. Tampilan Sense Making

Gambar 5 menampilkan Space Sense Making di instansi Kearsipan digunakan untuk menyimpan dan menyebarluaskan pengetahuan, didalamnya berisi aplikasi "SIAP" yang digunakan untuk menyimpan arsip pribadi, selain aplikasinya juga terdapat panduan penggunaannya. Pada gambar 2 pengguna dapat berdiskusi untuk mendapatkan pengetahuan yang dibutuhkannya. Space ini dapat mempermudah pegawai dalam menyimpan arsip yang dimiliki dengan fitur unggah file sehingga akan tersimpan pada Space yang tersedia hal ini dapat mengurangi resiko dari hilangnya pengetahuan yang dimiliki oleh instansi, selain itu penyebarluasan juga dapat dipermudah karena semua pegawai yang bekerja di instansi tersebut dapat membaca ataupun menggunduhnya, apabila ada kesulitan atau pertanyaan pegawai dapat langsung menuliskan komentar pada kolom yang ada pada Space.

Decision log
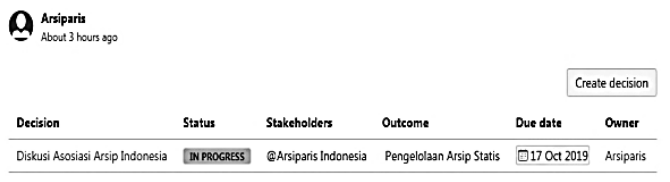

$B$ like Be the first to fike this

No labels

a wite comment-

Gambar 6. Tampilan Decision Log

Gambar 6 menampilkan fitur lain dari Space Sense Making adalah decision log yang digunakan untuk menampilkan hasil-hasil diskusi yang telah dilakukan, pada gambar berisi tentang keputusan hasil diskusi yang dilakukan oleh arsiparis Indonesia yang berisi tentang pengeloalaan arsip statis. 
22 Jurnal Teknologi Informasi dan Ilmu Komputer (JTIIK), Vol. 8, No. 1, Februari 2021, hlm. 15-26

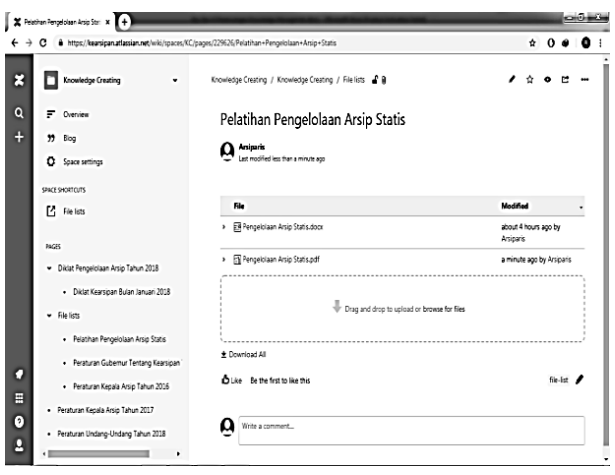

Gambar 7. Tampilan Knowledge Creating

Gambar 7 menampilkan Space Knowledge Creating digunakan untuk menyimpan pengetahuanpengetahuan yang dapat dilihat pada File Lists yang berisi pengetahuan dalam bentuk softfile yang berisi seperti Pelatihan Pengelolaan Arsip Statis, Peraturan Gubernur Tentang Kearsipan, dll. Arsip yang ada pada space dapat di unduh serta dapat di tambahkan file lain. Space ini mempermudah dalam penyimpanan arsip pengetahuan karena daftar pengetahuan yang sudah diunggah terdapat pada list, dan pegawai instansi dapat memanfaatkannya tanpa harus menghubungi pegawai yang mengunggahnya, dan ketika pegawai ada pertanyaan dapat langsung bertanya pada kolom komentar.

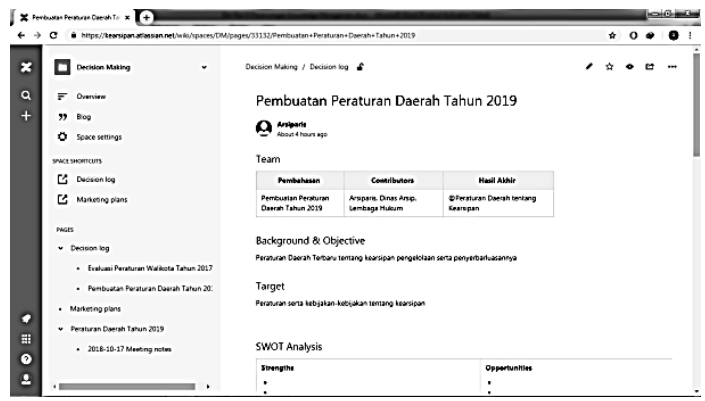

Gambar 8. Decision Making

Gambar 8 menampilkan Space Decision Making berisi tentang keputusan ataupun jadwal serta hasil-hasil evaluasi pada gambar menunjukkan hasil dari pembahasan pembuatan peraturan daerah tahun 2019 yang dilakukan oleh arsiparis, dinas arsip dan lembaga hukum memperoleh hasil akhir tentang peraturan daerah tentang kearsipan, didalamnya juga terdapat latar pembahasan, objek dan target, pada space ini berisi pages yang menampilkan halaman tetang evaluasi Peraturan Walikota tahun 2017, selain itu juga terdapat jadwal yang akan dilakukan tentang rapat peraturan daerah.

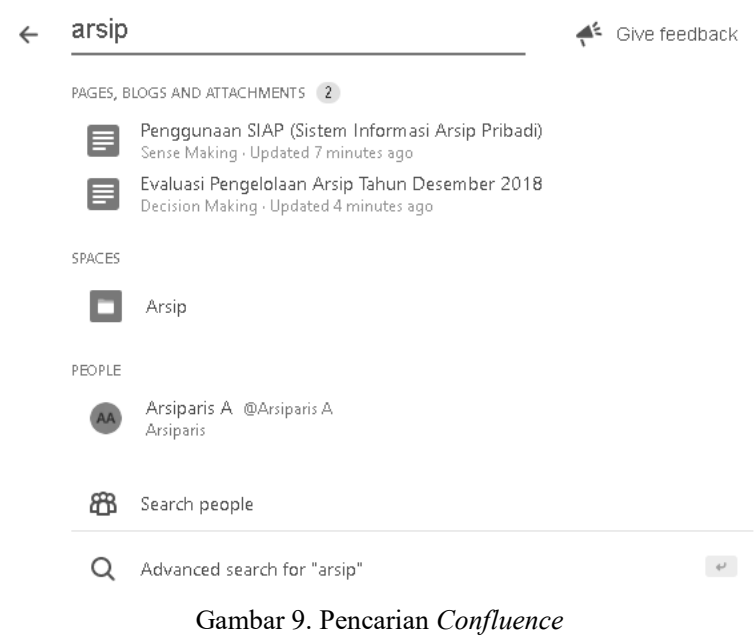

Pada gambar 9 menampilkan halaman pencarian yang dapat digunakan oleh pegawai instansi kearsipan, contoh pada gambar ketika diketikkan kata kunci "arsip" maka semua pengetahuan yang sudah diunggah di space akan ditampilkan dari page, blogs, space, dan pengguna lain. Hal ini dapat mempermudah pengguna ketika mencari pengetahuan yang sesuai dengan kebutuhan yang dibutuhkannya.

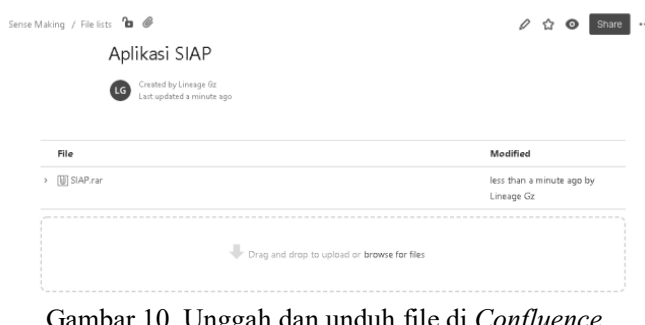

Gambar 10 menampilkan halaman unggah dokumen maupun file, ketika pegawai ingin mengunggah dapat mengklik browse for file, selain itu pegawai dapat membatasi siapa saja yang dapat melihat dokumen tersebut dengan tombol gembok, hal ini dapat mempermudah pegawai dalam mempublikasi dan membagikan informasi yang sesuai dengan kebutuhan instansi, selain itu ketika dokumen sesuai dengan kebutuhannya pegawai lain dapat mengunduhnya dengan mengklik dokumen yang dimaksudkan, hal ini mempermudah berbagai pengetahuan karena tidak harus izin terlebih dahulu kepada pemilik dokumen/ file tersebut.

Penerapan Knowledge Management dengan menggunakan tools Confluence, dengan pembagian space sesuai dengan pembagian model Choo-Sense Making dapat mengatur pendokumentasian pengetahuan yang dimiliki oleh instansi, penerapan ini memudahkan pegawai untuk mempelajari tentang 
arsip dan pengelolaannya, pengetahuan tentang instansi arsip, pengelolaan arsip, teknologi yang berkembang untuk pengelolaan arsip. Penerapan ini dapat membawa keuntungan untuk instansi karena pegawai secara akurat belajar tentang arsip dan pengelolaannya, hal ini dapat mempercepat proses pengelolaan arsip dan penyebarluasaannya.

Orang membuat atau secara aktif membangun lingkungan yang mereka geluti dengan mengelompokkan pengalaman, dan dengan menciptakan pengetahuan baru di lingkungan. Sensemaking disebabkan oleh perubahan dalam lingkungan yang menciptakan pengetahuan dari pengalaman yang melibatkan orang dan kegiatan organisasi. Organisasi kemudian menciptakan pengetahuan baru dengan mengkonversi antara pengetahuan dan mengintegrasikan serta menggabungkan pengetahuan dan memperoleh atau mentransfer pengetahuan. Transfer pengetahuan dengan baik tersebut biasanya membutuhkan sejumlah besar pengetahuan dalam organisasi penerima untuk memecahkan kode dan menerapkan informasi baru. Sejumlah besar kasus, transfer pengetahuan eksplisit disertai dan difasilitasi oleh para pakar manusia dari organisasi. Model ini juga menyiratkan bahwa semakin besar interaksi antara proses pembuatan pengetahuan, penciptaan pengetahuan, dan pengambilan keputusan, semakin besar kapasitas organisasi untuk mendeteksi ancaman dan peluang, menciptakan pengetahuan yang berharga, dan bertindak berdasarkan pengetahuan baru (Choo: 2001). Model Choo-Sense Making ini dapat membuat instansi kearsipan memberikan kemudahan instansi dalam mengelompokkan pengetahuan dan kemudian menciptakan pengetahuan baru berdasarkan pengalaman dan kemudian menyebarluaskan pengetahuan tersebut dalam lingkungan instansi dengan Confluence.

Berdasarkan hasil suvey di instansi kearsipan, Knowledge Management yang dirancang sesuai dengan kebutuhan instansi kearsipan, karena mudah penyimpanan gambar, dokumen, foto hal ini memudahkan pegawai dalam menyimpan hasil dokumentasi, sistem yang online memudahkan pegawai karena di instansi sudah terdapat wifi dan internet, sehingga semua pegawai bisa menggunakan sistem tersebut termasuk juga untuk berbagi atau penyebarluasan arisp antar pegawai. Perancangan Knowledge Management di instansi kearsipan dalam space bisa ditambahkan bidang-bidang kearsipan seperti, pelayanan arsip statis, arisp kuno, arsip pribadi, arsip dinamis, arsip alih media dll, koordinasi dengan pegawai lain dapat dilakukan dengan cepat dengan penambahan media koordinasi ketika ada rapat, evaluasi, pertemuan maupun event-event. Pelatihan kepada pegawai instansi tentang sistem Knowledge Management ini diperlukan secara berkala agar seluruh pegawai dapat menggunakannya sesuai dengan jobdesk pegawai kearsipan, secara tampilan sistem ini menarik dan mudah digunakan, fiturnya juga sesuai dengan kebutuhan instansi.

\section{KESIMPULAN}

Hasil penelitian yang dilakukan, memperoleh simpulan sebagai berikut, Explicit Knowledge diperoleh dari pelatihan-pelatihan diklat yang diikuti dan mendapatkan laporan yang berisi kegiatan diklat, peraturan walikota, peraturan kepala arsip, peraturan gubernur, serta peraturan undangundang tentang pengelolaan arsip, penyimpanan pengetahuan ini masih dilakukan secara personal masing-masing pegawainya. Penelitian ini menghasilkan sebuah penerapan aplikasi Knowledge Management yang dapat digunakan oleh instansi untuk mengelola pengetahuan yang dimiliki agar dapat disebarluaskan oleh semua pegawai yang bekerja di instansi kearsipan, penelitian ini menerapkan model Knowledge Management dengan menggunakan Choo-Sense Making yang membagi masing-masing pengetahuan dan diterapkan ke dalam space yang terdapat pada Confluence sehingga dengan penerapan ini dapat menghindari hilangnya pengetahuan yang dimiliki oleh instansi, mempermudah penyebarluasan dan penyimpanan informasi dan sebagai media diskusi pegawai instansi. Penerapan model Choo-Sense Making memperoleh hasil untuk Sense Making berupa pengetahuan-pengetahuan dari luar seperi dari pihak AAI (Asosiasi Arsiparis Indonesia) yang dibuatkan wadah untuk saling berdiskusi, bertukar pengetahuan dan chatting, selain itu juga Aplikasi-aplikasi yang digunakan untuk mengelola arsip-arsip yang ada akan ditampung dalam space sehingga memudahakan dalam menemukan dan penyebarlaskannya. Knowledge Creating memperoleh hasil berupa softfile ataupun hardfile yang berisi tentang peraturanperaturan yang digunakan dalam pengelolaan arsip, serta laporan-laporan hasil pelatihan, laporan diklat, laporan sosialisasi yang diunggah ke dalam space. Decision Making berisi tentang jadwal kegiatan kearsipan, serta evaluasi-evaluasi yang dilakukan instansi dalam penerapan yang dilakukan di instansiinstansi yang ada, serta keputusan-keputusan yang telah dibuat.

Penerapan Confluence pada Knowledge Management yang dimiliki oleh instansi kearsipan sesuai dengan model Choo-Sense Making 
24 Jurnal Teknologi Informasi dan Ilmu Komputer (JTIIK), Vol. 8, No. 1, Februari 2021, hlm. 15-26

memperoleh hasil Space Sense Making berisi tentang diskusi-diskusi pegawainya, serta aplikasi-aplikasi yang ada di bidang kearsipan dan arsip yang berupa file, maupun informasi dan pedoman penggunaannya. Space Knowledge Creating berisi tentang Softfile tentang peraturan-peraturan kearsipan, laporanlaporan diklat, sosialisasi dll, yang berisi pembahasan yang dapat digunakan untuk mengelola arsip. Decision Making berisi tentang pedoman jadwal, serta evaluasi-evalusi yang dilakukan oleh instansi dalam mengelola arsip.

Penerapan model Choo-Sense Making mengelompokkan jenis-jenis pengetahuan yang dimiliki oleh instansi kearsipan sehingga memudahkan pencarian pengetahuan yang dibutuhkan oleh pegawainya. Penerapan Confluence menghemat biaya penyimpanan, serta ruang dalam penyimpanan, selain itu memudahkan penyebarluasan pengetahuan kepada pegawai lain yang membutuhkan, Confluence juga dapat dijadikan media diskusi bagi pegawai ketika menemukan masalah serta mencari solusinya.

Saran yang untuk pengembangan lebih lanjut, model Choo-Sense Making serta Confluence dapat diterapkan sebagai uji coba untuk memperoleh gambaran sesuai tidaknya jika diterapkan di Instansi Kearsipan, yang dapat dijadikan pengembangan instansi kearsipan untuk memperoleh hasil yang maksimal

Instansi dapat menerapkan metode ini dengan menggabungkan dengan metode lain untuk mendapatkan hasil yang sesuai dengan kebijakan dan peraturan yang ada di masing-masing instansi kearsipan.

\section{DAFTAR PUSTAKA}

ALAM, MD. MAHBUBUL. 2015. Knowledge Management Models. Dhaka: AEISSher-eBangla Agricultural University.

CALDWELL, TERRENCE. 2015. Confluence 101: Getting Started in Confluence. Australia: Atlassian Confluence.

CHOO, CHUN WEI. 2001. Sensemaking, Knowledge Creation, and Decision Making: Organizational Knowing as Emergent Strategy. Toronto: Faculty of Information Studies University of Toronto.

CRISTEA, DRAGOS SEBASTIAN. (2009). Perspectives on Knowledge Management Models. Romania: The Annals of "Dunarea de Jos" University of Galati.

DARUDIATO, SUPARTO. (2013). Knowledge Management: Konsep dan Metodologi. Ultima
InfoSys Jurnal Sistem Informasi 4(1): Universitas Bina Nusantara.

ELVINA, IRMA. 2010. Bisnis Informasi dalam Konteks Knowledge Management. Jurnal Pustakawan Indonesia Volume 10 (1): Perpustakaan IPB.

HOUSMAND, MAHMOUD. 2017. A Road Map for Knowledge Management Systems Design Using Axiomatic Design Approach. International Conference on Axiomatic Design: MATEC Web of Conferences 127.

ISKANDAR, KARTO. 2014. Perancangan Knowledge Management System Menggunakan Tools "Book Review" : Studi Kasus Pada Universitas Bina Nusantara. ComTech 5 (2): BINUS University.

KOSASIH. 2000. Sekilas Tentang Knowledge Management. Ilmu Komputer, Bandung.

LEGIAWAN, MOHAMAD KANY. 2015. Penerapan Model Choo-Sense Making pada Rancangan Knowledge Management System (KMS) untuk Meningkatkan Mutu Kinerja Karyawan di Universitas Suryakancana. Media Jurnal Informatika 7(2): Universitas Suryakancana.

MOHAJAN, HARADAN. 2017. The Impact of Knowledge Management Models for the Development of Organizations. Journal of Environmental Treatment Techniques 2017 5(1): Munich Personal RePEc Archive.

MULYANTO, AGUS. 2009. Roadmap Implementasi Knowledge Management. Seminar Nasional Informatika: UPN "Veteran" Yogyakarta.

PERDANA, ERIC MEGAH, DANNY MANONGGA, ADE IRIANI. 2019. Model Konseptual bagi Pengembangan Knowledge Management di Sma Menggunakan Soft System Methodology. Jurnal Teknologi Informasi dan Ilmu Komputer (JTIIK): Universitas Brawijaya.

RAZMERITA, LIANA. 2016. Innovations in Knowledge Management The Impact of Social Media, Semantic Web and Cloud Computing. New York: Springer.

RIYADI, ARIS. 2016. Penerapan Knowledge Management: Oral History Penanganan 
Arsip Bencana Topan Haiyan di Filipina. Jurnal Baca PDII LIPI 37(2): LIPI.

SAPUTRA, RICKY RINALDI. 2012. Evaluasi Software Otomigen $\mathrm{X}$ sebagai Sistem Layanan Informasi di Fikom and Knowledge Center dengan pendekatan Analisis SWOT. eJurnal Mahasiswa 1(1) : Universitas Pajadjaran.

XIAOJUN, ZHU. 2014. Archives Management System Design Based on Oracle. Switzerland: Trans Tech Publications. 
Halaman ini sengaja dikosongkan 